\title{
Home Under Care of Organized Home Health Service Organization in Anticipation of Covered Skilled Care
}

National Cancer Institute

\section{Source}

National Cancer Institute. Home Under Care of Organized Home Health Service

Organization in Anticipation of Covered Skilled Care. NCI Thesaurus. Code C99959.

Personal health maintenance at an individual's residence that is administered and monitored by a member of a healthcare org anization that is eligible to receive Medicare funding. (ACC) 